\title{
Proceeding
}

Supplementary Issue: Autumn Conferences of Sports Science. Costa Blanca Sports Science Events, 18-19 December 2020. Alicante, Spain.

\section{Data investigation on the performance-enhancing drugs spread in Italy among young athletes: Prevention trough education and the fight against doping in sport}

\author{
FILOMENA MAZZEO 1 , STEFANIA SANTAMARIA ${ }^{1}$, VALERIA DI ONOFRIO²
}

${ }^{1}$ Department of Motor Science and Wellbeing, Interdepartmental School of Science, Engineering and Health, University of Naples "Parthenope", Naples, Italy

${ }^{2}$ Department of Science and Technology, Interdepartmental School of Science, Engineering and Health, University of Naples "Parthenope", Naples, Italy

\begin{abstract}
Introduction: Substances and methods capable of improving athletic performance have been one of the greatest concerns in elite sport community. It is a serious danger to sport and health. The teacher, coach and educator play an important role in the "physically" training of educated people and in culture of health promotion. Methodology: The study combines a bibliographic research about education importance in doping prevention and the Italian data analysis in doping spread for attention among young athletes $(<19)$. The bibliographic sources were identified on Scopus, PubMed and ScienceDirect. The data relating about doping spread were extrapolated by reports of the Italian Ministry of Health. The time frame considered from 2018 (latest available data) to 2013. Results: The available data show that 2014 had the highest number of positives (58) and that, starting from that year, the doped athletes number was significantly lower up to 13 in 2018. On young people $<19$ an almost irrelevant positives number can be seen. Even in 2014 the positives number was 0 . Conclusion: This study shows data on the doping prevalence and the result of WADA's identification of educational programs and research on social prevention as strategic priorities for the development of evidence-based anti-doping education.
\end{abstract}

Keywords: Doping; Drug; Prevention; Education; Health; WADA.

Cite this article as:

Mazzeo, F., Santamaria, S., \& Di Onofrio, V. (2021). Data investigation on the performance-enhancing drugs spread in Italy among young athletes: Prevention trough education and the fight against doping in sport. Journal of Human Sport and Exercise, 16(2proc), S705-S715. doi:https://doi.org/10.14198//hse.2021.16.Proc2.56

Corresponding author. Department of Science and Technology, Interdepartmental School of Science, Engineering and Health, University of Naples "Parthenope", Business District, Block C4, 80143 Naples, Italy. https://orcid.org/0000-0001-9398-3496 E-mail: valeria.dionofrio@uniparthenope.it

Abstract submitted to: Autumn Conferences of Sports Science. Costa Blanca Sports Science Events, 18-19 December 2020. Alicante, Spain.

JOURNAL OF HUMAN SPORT \& EXERCISE ISSN 1988-5202

(c) Faculty of Education. University of Alicante

doi:10.14198/jhse.2021.16.Proc2.56 


\section{INTRODUCTION}

Sport play an essential role in the life of every individual. It brings significant psychophysical and social benefits (Mazzeo \& Di Onofrio, 2019). Specifically, it allows the diffusion of important values that in particular help young people to making the most of their abilities to control their character and to respect themselves and others: from the opponent to the coach to the sports authorities (Montesano \& Mazzeo, 2019; Wang et al., 2020).

Moreover, sport is an essential component for the psychophysical development of people and a socially important phenomenon (Montesano et al., 2020). According to Mauss (Mauss, 1950) it is a complex of activities that includes different areas ranging from purely sports to politics. Sport, likewise, represents an important educational tool for the population especially young people. It is therefore essential that society instils the spirit of sport in the entire population (Mazzeo, 2016; Montesano, 2019b). According to 2021 Wada Code (WADA, 2021) "the spirit of sport is the celebration of the human spirit body and mind. It is the essence of Olympism and is reflected in the vales we find and through sport including: health; ethics fair play and honestly; athletes' rights excellence in performance; character and education; fun and joy; teamwork; dedication and commitment; respect for rules and laws; respect for self and other participants; courage; community and solidarity". The diffusion of the abovementioned values helps young people to making the most of their abilities to control their character and to respect themselves and others: from the opponent to the coach to the sports authorities. Moreover, athletes with excessive perfectionism, extrinsically motivated and who have interaction with drugs have a positive attitude toward doping (Montesano et al., 2013; Zucchetti et al., 2015; Mazzeo et al., 2019).

It is necessary for the young athlete to be well aware that only through commitment can obtain excellent results and that defeat is not a personal failure but simply an adverse result (Mazzeo, et al., 2020). Unfortunately, today's society and the sports world are undermining the values of sport. The culture of perfectionism together with the pressure of sports clubs towards excellent results in order not to lose the support of the sponsors are "forcing" athletes to seek the result at any cost (Montesano et al., 2016).

If all this is combined with the loss of the transmission of values by parents it is easy to understand how the doping culture finds fertile ground. Indeed, especially in the digital age in which young people are completely dependent on social media and digital communication the fake news on the effects of food and ergogenic supplements spread rapidly negatively influencing the choices of the younger population (Montesano et al., 2020; Mazzeo et al., 2020). Let it be clear that the search for victory and the best result has ancient origins but the difference from the past is the exorbitant spread of the phenomenon even through substances that are highly harmful to health. Substances and methods capable of improving athletic performance have been one of the greatest concerns in elite sport community (Madrak et al., 2018).

Today the phenomenon is well known under the term "doping" a complex phenomenon that damages the spirit of sport and represents a serious problem of order and public health (Mazzeo \& Di Onofrio, 2019).

In the study conducted by Mudrak (Mudrak, et al., 2018) on a sample of 1035 adolescents it was found that $59 \%$ intend to take drugs while $17.6 \%$ have doping behaviours. The author notes that despite the use of doping substances is a prevalent to young athletes there is little attention to the phenomenon. A lot of drugs are used in sport. So, non-steroidal anti-inflammatory drugs (NSAIDs) are medications that are frequently used by athletes and the existence of an ergogenic effect of NSAIDs are discussed (Cornu et al., 2020; Schenone et al., 2003; Motola et al., 2001; Mazzeo,2016). Anti-doping education programs during the last 
years has increased (Codella, Glad, Luzi, \& La Torre, 2019; Mazzeo et al., 2018), it is worth to have more analysis of such studies.

Moreover, education programs continue to play a central role in WADA's overall anti-doping strategy. The purpose of this research was to provide an overview of research focusing on anti-doping education programs and being put on 'prevention' in the fight against doping in sport.

\section{METHODS}

The article is based on a bibliographic research going on the importance of education as doping prevention and the analysis of data on the spread of doping in Italy for attention among young athletes $(<19)$. The data were collected from various sources: official documents from institutions, Scopus PubMed and ScienceDirect. The data relating to the spread of doping were extrapolated from the reports of the Italian Ministry of Health and published on its official website. The time frame considered for this study is 5 years from 2018 - the last year in which the data are available - to 2013.

\section{RESULTS}

The Figure 1 show total of tests and positives in Italy (Breakdown from 2013 to 2018) and in 2018, the highest percentage of active substances detected at doping controls belonged to: cannabinoids $33.3 \%$, anabolic agents $26.7 \%$ and stimulants $26.7 \%$.

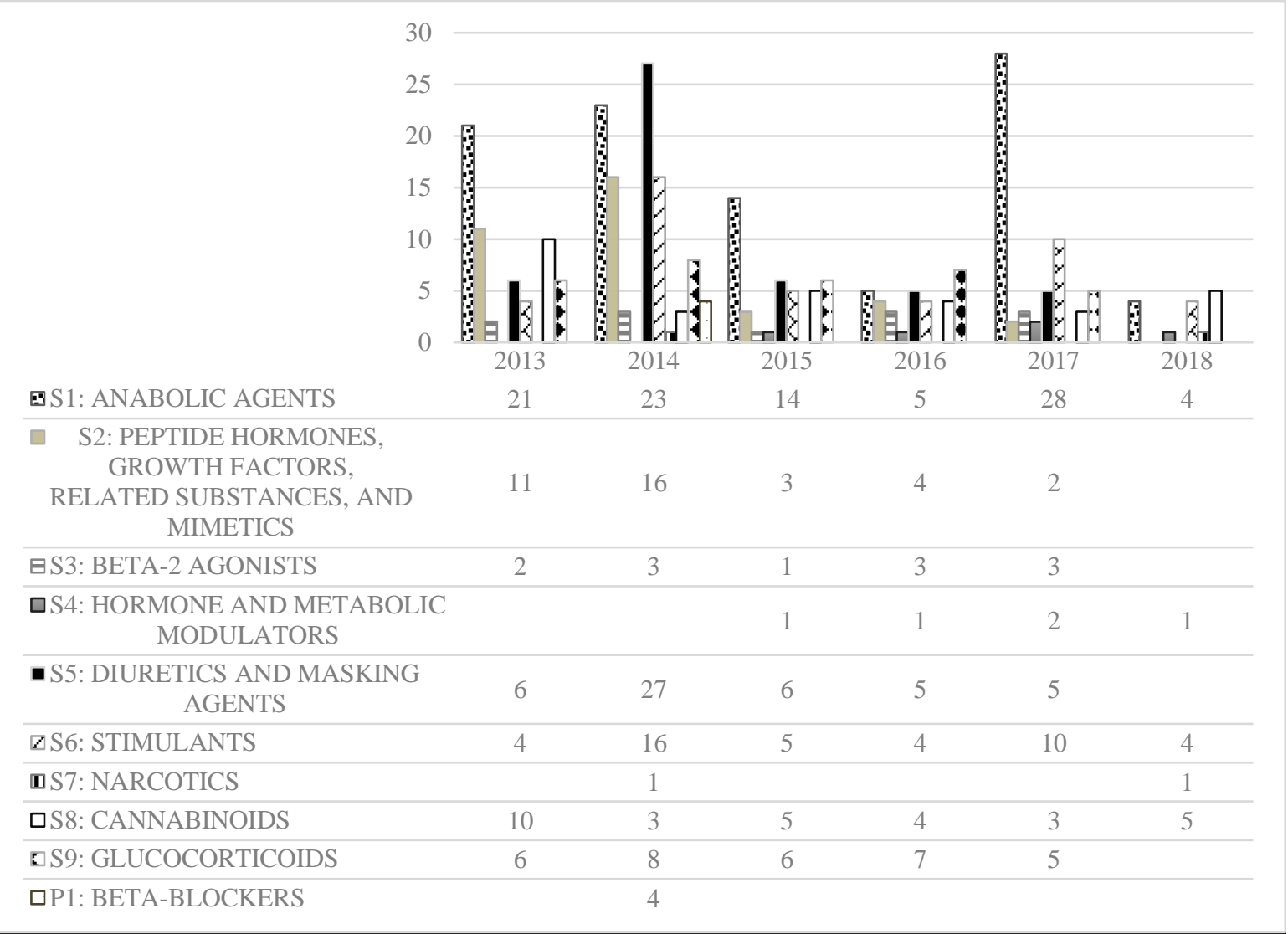

Figure 1. Spread of doping substances. Breakdown from 2013 to 2018. 
The Table 1 the athlete nationalities with the highest number of Anti-Doping Rule Violations.

Table 1. The athlete nationalities with the highest number of Anti-Doping Rule Violations. Breakdown from 2014 to 2017. Source: https://www.wada-ama.org/

\begin{tabular}{|c|c|c|c|}
\hline 2017 & 2016 & 2015 & 2014 \\
\hline $\begin{array}{l}\text { - Italy - } 171 \\
\text { - } \text { France - } 128 \\
\text { - USA - } 103 \\
\text { - Brazil - } 84 \\
\text { - Russian } \\
\text { Federation - } 82 \\
\text { - China - } 62 \\
\text { - India - } 57 \\
\text { - Belgium - } 54 \\
\text { - Spain - } 52 \\
\text { - South Africa - } 43\end{array}$ & $\begin{array}{l}\text { - Italy - } 147 \\
\text { - France - } 86 \\
\text { - USA - } 76 \\
\text { - Australia } 75 \\
\text { - Belgium - } 73 \\
\text { - India - } 69 \\
\text { - Russia - } 69 \\
\text { - Brazil - } 55 \\
\text { - Iran } 55 \\
\text { - South Africa - } 50\end{array}$ & $\begin{array}{l}\text { - Russian } \\
\text { Federation - } 176 \\
\text { - Italy - } 129 \\
\text { - India - } 117 \\
\text { - France - } 84 \\
\text { - Belgium - } 67 \\
\text { - South Africa - } 59 \\
\text { - Turkey - } 59 \\
\text { - Republic of } \\
\text { Korea -51 } \\
\text { - USA - } 50 \\
\text { - Iran - Republic of } \\
\text { Islamic - } 48\end{array}$ & $\begin{array}{l}\text { - Russian } \\
\text { Federation - } 148 \\
\text { - Italy - } 123 \\
\text { - India - } 96 \\
\text { - Belgium - } 91 \\
\text { - France - } 91 \\
\text { - Turkey - } 73 \\
\text { - Australia - } 73 \\
\text { - Australia - } 49 \\
\text { - China - } 49 \\
\text { - Brazil - } 46 \\
\text { - Republic of } \\
\text { Korea - } 43\end{array}$ \\
\hline
\end{tabular}

Firstly, you have to consider that over the years the number of controls has varied and consequently the number of positive athletes too. The available data shows that 2014 had the highest number of positives (58) and that starting from that year the number of doped athletes was significantly lower up to 13 in 2018 (Figure 2).

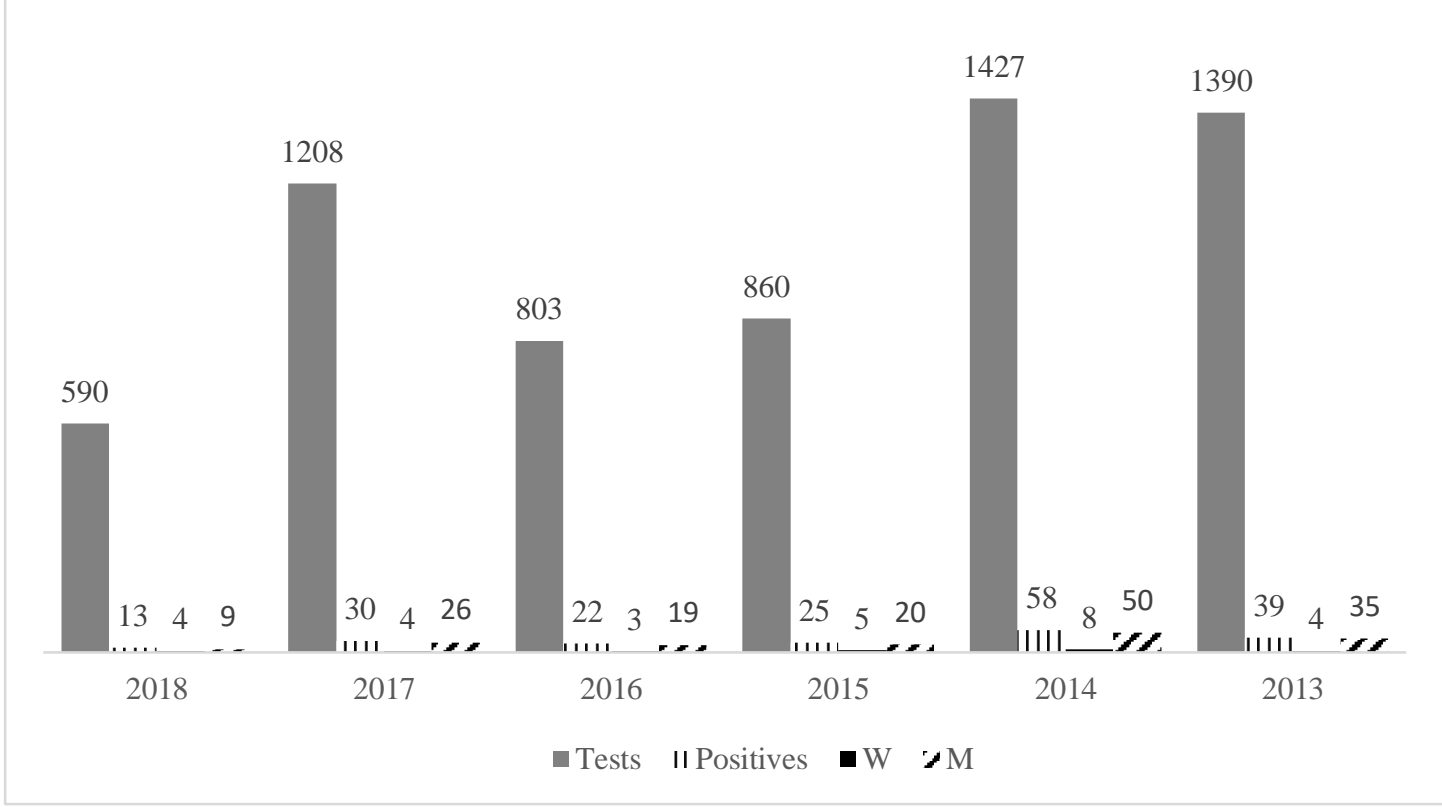

Figure 2. Total of tests and positives in Italy. Breakdown from 2013 to 2018. 
The constant throughout the period considered was that men dope more than women. By focusing attention on young people <19 an almost irrelevant number of positives can be seen. Even in 2014 the number of positives was 0 (Table 2, Figure 3).

Table 2. The spread of doping among <19 athletes. Breakdown from 2013 to 2018.

\begin{tabular}{ccc}
\hline Year & Checked $<19$ & Positives $<19$ \\
\hline 2018 & 133 & 1 \\
2017 & 242 & 2 \\
2016 & 143 & 1 \\
2015 & 220 & 1 \\
2014 & 259 & 0 \\
2013 & 301 & 2 \\
\hline
\end{tabular}



Figure 3. Doping spread in Italy to 2013 from 2018 with and a focus of age $<19$.

From the analysis of the data (data not shown), it is possible to observe that over the years the average age of positive subjects has not suffered significant fluctuations, apart from a maximum value recorded in 2014 (43 years). More generally, by stratifying the sample of athletes who tested positive for controls into age groups anti-doping, it is possible to observe the trend, over the years, to detect the highest percentage of positive among the more mature athletes ( $\geq 44$ years), while the lowest among the under 19 , trend also confirmed with regard to the 2013-2018 data. Furthermore, in 2018, the highest percentages of positivity in relation to the number of athletes controlled, were recorded in athletes aged between 34 and 38 years (4.7\%), while the lowest percentage was recorded among athletes under the age of $19(1.1 \%)$. 
Indeed, in Table 3 were indicate the studies that investigate the effects of intervention on the decision-making process relevant to doping among elite athletes who were doping users, study on education as doping prevention and on analysis of data on the spread of doping.

Table 3. Studies on education as doping prevention and on analysis of data on the spread of doping.

\begin{tabular}{|c|c|c|}
\hline Study & Sample & Type of detection \\
\hline Barkoukis et al. - 2015 & $\begin{array}{l}650 \text { Greek athletes aged } \\
\text { between } 14 \text { and } 20 \text { yr. }\end{array}$ & Questionnaires \\
\hline Barnes et al. -2020 & Coaches & Literature review \\
\hline Blank et al. - 2016 & $\begin{array}{l}1265 \text { Austrian athletes aged } \\
\text { between } 14 \text { and } 19 \mathrm{yr} \text {. }\end{array}$ & Questionnaires \\
\hline Blank t al. - 2015 & 883 Austrian parents & Questionnaires \\
\hline Blashill et al. - 2017 & $\begin{array}{l}6248 \text { American athletes aged } \\
\text { between } 14 \text { and } 18 \mathrm{yr} \text {. }\end{array}$ & Questionnaires \\
\hline Chan et al. - 2015 & 410 Australian elite athletes & Behaviour Analysis \\
\hline Giraldi et al. - 2015 & $\begin{array}{l}423 \text { Italian soccer players } \\
\text { between } 15 \text { and } 18 \mathrm{yr} \text {. }\end{array}$ & Questionnaires \\
\hline Laure et al. - 2004 & $\begin{array}{l}1459 \text { French high school } \\
\text { students }\end{array}$ & Behaviour Analysis \\
\hline Laure et al. - 2007 & $\begin{array}{l}3564 \text { French students between } \\
11 \text { and } 12 \mathrm{yr} \text {. }\end{array}$ & Questionnaires \\
\hline Lucidi et al. - 2004 & $\begin{array}{l}952 \text { Italian athletes between } 14 \\
\text { and } 20 \mathrm{yr} \text {. }\end{array}$ & Questionnaires \\
\hline Lucidi et al. - 2008 & 1232 Italian high school athletes. & Questionnaires \\
\hline Lucidi et al. - 2013 & $\begin{array}{l}1975 \text { Italian athletes between } 13 \\
\text { and } 18 \mathrm{yr} \text {. } \\
\text { test controls and combined the }\end{array}$ & Questionnaires \\
\hline Mazzeo et al. -2020 & $\begin{array}{l}\text { information on the consumption } \\
\text { of doping substances }\end{array}$ & Behaviour Analysis \\
\hline Nicholis et al. - 2015 & $\begin{array}{l}11 \text { coaches from different } \\
\text { countries }\end{array}$ & Interviews \\
\hline Turman - 2007 & 30 parents & Interviews \\
\hline
\end{tabular}

\section{DISCUSSION}

There are many studies on health damage and violations of anti-doping legislation (Mazzeo et al., 2020; Mazzeo et al., 2019; Woolf, 2020). However, to be correctly interpreted - and fought - doping must also be seen as a cultural and educational problem (Isidori, 2017) and is studied as an ethical problem that has medical and legal riots (Mazzeo et al., 2018; Barkoukis et al., 2019). Therefore, in order to defeat this disease of sport in addition to the controls ordered by the various sports authorities and sanctions an educational approach is necessary as a preventive measure (Wang, et al., 2020). Indeed, Doping is closely linked to a lack of "educational agents" such as family school religious associations federations and sports clubs (Goldberg,2005; Wang et al., 2020).

It is therefore necessary to educate the athlete in the conscious use of their will and respect for themselves and others (Di Onofrio et al., 2019; Woolf, 2020). Pedagogy therefore is a necessary component in doping 
prevention. It is equally necessary that anti-doping education is designed for all people involved in sports especially the younger generations (Woolf, 2020).

But before building an educational protocol it is necessary to understand why young people have a doping behaviour or intend to do it. Many studies show that those who have low self-esteem and constantly seek the approval of others are more likely to use performance-enhancing drugs. These subjects classified as ego-oriented people find the best result not for themselves but for the others and experience defeat as a personal failure to be ashamed of (Duda et al., 1995; Mazzeo, 2019).

Moreover, Mudrak (Mudrak, et al., 2018) believes that the adolescents most prone to doping are those who show moral disengagement from doping and feel supported by the use of doping substances by others. Furthermore, these subjects have a poor status in the group to which they belong live the anxiety of acceptance suffer from depression and already use substances that give a gratifying effect even if temporary.

In fact, the reward effect is an important component of drug use. It can be direct and indirect. According to Mazzeo (Mazzeo et al.,2018; Mazzeo et al., 2019) the drugs dependence could be connected to the indirect gratification. It consists in all situations in which the person has a social economical or psychological benefit thanks to use drugs. For example: the direct gratification is linked to the winning of a competition and indirect gratification in the money that the athlete receives after. If all the gratifications are connected to use of drug maybe the athletes will use drug in the future. Another important factor that leads young people to use doping substances is the aesthetic one. Indeed, more and more people are desperately trying to lose weight and gain muscle in a short time and with minimal effort (Madrak et al., 2018).

For the reasons discussed above, once understood the reasons that push young athletes to take drugs it is necessary to draw a specific educational protocol. Many scholars have pointed out that almost 50 years ago students complained about the quality of anti-doping education due to the excessive technicality used and inappropriate argument for the recipients (Woolf et al., 2020). Another relevant problem is the lack of homogeneity of the educational campaigns promoted and the lack of coordination between organizations sporting and non - regional national and international (Mazzeo et al., 2018).

Anyway, according to scholars (Goldberg L. \& Elliot, 2005) D ATLAS (Adolescents Training and Learning to Avoid Steroids) and ATHENA (Athletes Targeting Healthy Exercise and Nutrition Alternatives) programs are the best educational approach. Developed at the American University of Oregon they are addressed to high school students engaged in sports activities. The two programs have been very successful thanks to the peer education method. But not only, they indeed focused on the reduction of the main risk factors (peer pressure false marketing beliefs) and on the development of various protective aspects (adequate training program nutrition confidence in one's athletic abilities).

Another important educational program is entitled "Hercules" whose starting point is the awareness that drug use depends on the environment in which the individual develops (Backhouse, 2015). The Hercules program provides adolescents with a solid theoretical foundation on: basic principles of exercise and strength training biomechanics of strength training nutrition and dietary supplementation sports ethics anti-doping anabolic steroids and their adverse health effects. Its strength is the union of anti-doping education with practical strength training (Backhouse, 2016; Mazzeo et al., 2018).

ATLAS ATHENA and Hercules' programs are based on the observation of behavioural models their understanding and subsequently through the imitation of positive behavioural (Woolf,2020). Similarly, 
Barkoukis (Barkoukis, 2016) designs an educational program based on the use of positive behavioural models such as professional athletes in order to influence the choices of the younger generation of athletes.

Over the years, there have been several theories on the design of adequate educational anti-doping programs but currently the primary source is represented by World Anti-Doping Agency (WADA) which has elected anti-doping education as a preventive measure. Indeed, in January 2018 the Agency launched an elearning platform (ADeL) which offers access to all topics related to clean sport and anti-doping. Moreover, it offers courses for athletes coaches doctors administrators and anyone interested in learning more about antidoping and protecting the values of clean sport (WADA, Anti-Doping E- Learning, 2020). It includes various modules: ALPHA Coach True Parent's Guide Sport Physician's Toolkit. The ALPHA module is structured in a series of lessons about the dangers of doping and the importance of anti-doping controls and promotes positive attitudes to avoiding doping. It concludes with an attitude survey followed by a 12 -item multiple choice test to assess athletes' knowledge. On the other hand, Coach True Parent's Guide and Sport Physician's Toolkit are online tutorial programs targeted at specific populations (Wolf,2020).

WADA before building anti-doping campaigns makes an important difference between information and education (WADA 2021); the first one deals with providing knowledge while the second one has the task of promoting behaviour. To date WADA is a reference point for the anti-doping education thanks to its International Standard for Education (ISE) introduced in 2009 on the occasion of the World Conference on Doping in Sport held in Katowice (Poland). According to WADA (WADA, 2020) the starting point of the ISE is that the athlete's first anti-doping experience must be through education rather than through controls and the education should begin early preferably in school age.

The main objective that through ISE WADA intends to pursue is the harmonization of anti-doping education through the imposition of mandatory standards for the signatory countries.

According to Standard WADA recommends to signatories to develop and deliver an education program based on the knowledge and dissemination of the various negative aspects related to doping and the impotence of sporting values. The ultimate goal of the educational program is to develop an ethical awareness of the behaviours to be assumed through the discussion of topics and issues related to clean sport.

\section{CONCLUSION}

The anti-doping fight inexorably passes through controls and eventually through sanctions. But the first approach that athletes especially the younger ones must have with the anti-doping culture is through information and education campaigns. They must be characterized by uniformity at every level and must be suitable for the reference target. It is hoped that they should be of interest to school-age children in order to influence their choices by understanding the values of sport and which models to follow and emulate.

Further research studies, especially on young athletes, and include their coaches, instructors and other persons close to them, which examine athletes' belief system and provoke critical thinking in athletes about using banned substances in sport might be more effective in preventing doping as well as programs focusing on health education.

Over the years various theories have followed one another but to date once again WADA sets itself as a reference point in the fight against doping through its guidelines on information and education. It is therefore 
hoped that these preventive measures can over time give excellent results in order to reduce the number of positives in every age group and in every category.

\section{REFERENCES}

Backhouse S. H., Anti-doping education for athletes. Møller V., Waddington I., Hoberman J.M., (Eds.). Routledge handbook of drugs and sport. Routledge London. 2015;229-238. https://doi.org/10.4324/9780203795347-20

Barkoukis, V., Brooke, L., Ntoumanis, N., Smith, B., \& Gucciadi, D. F. (2019). The role of the athletes' entourage on attitudes to doping. Journal of Sports Sciences, 37(21), 2483-2491. https://doi.org/10.1080/02640414.2019.1643648

Barkoukis V., Kartali K., Lazuras L., Tsorbatzoudis H., Evaluation of an anti-doping intervention for adolescents: Findings from a school-based study, Sport Management Review. 2016; 19 (1), 23-30. https://doi.org/10.1016/j.smr.2015.12.003

Codella, R., Glad, B., Luzi, L., \& La Torre, A. (2019). An Italian campaign to promote anti-doping culture in high-school students. Frontiers in Psychology, 10(534), 1-5. https://doi.org/10.3389/fpsyg.2019.00534

Cornu, C., Grange, C., Regalin, A., Munier, J., Ounissi, S., Reynaud, N., . . Nony, P. (2020). Effect of non-steroidal anti-inflammatory drugs on sport performance indices in healthy people: A metaanalysis of randomized controlled trials. Sports Medicine - Open, 6(1). https://doi.org/10.1186/s40798-020-00247-w

Di Onofrio V., Montesano P., Mazzeo F., Physical-technical conditions coaching and nutrition: An integrated approach to promote cohesion in sports team, Journal of Human Sport and Exercise. 2019;14 (Proc4), S981-S990. https://doi.org/10.14198//hse.2019.14.Proc4.60

Duda JL., Chi L., Newton ML., Walling MD., Task and ego orientation and intrinsic motivation in sport, Int J Sport Psychol. 1995; 26, 40- 63.

Goldberg L., Elliot DL., Preventing substance use among high school athletes: The ATLAS and ATHENA programs, J Appl Sch Psychol. 2005; 21(1): 63-97. https://doi.org/10.1300/J370v21n02_05

Isidori E., Pedagogia e sport. La dimensione epistemologica ed etico-sociale. Milano: Franco Angeli, 2017.

Mauss M., Les techniques du corps'. In: Sociologie et anthropologie. Paris: PUF, 1950.

Mazzeo F. \& Di Onofrio V., Sport drugs and health promotion: Pharmacological and epidemiological aspects, Sport Mont. 2019; 17 (2), 81-85. https://doi.org/10.26773/smj.190614

Mazzeo F., Attitude and practice of substance misuse and dietary supplements to improve performance in sport. Journal of Substance Use. 2019; 24 (6), 581-586. https://doi.org/10.1080/14659891.2019.1642410

Mazzeo F., D'elia F., Raiola G., Drugs in sport: Doping development and ethical analysis, Sport Science. 2018; 11(1), 106-112.

Mazzeo F., Monda V., Santamaria S., Nigro E.,Valenzano A., Villano I., Cibelli G., Messina A., Messina G., Antidoping program: An important factor in the promotion and protection of the integrity of sport and athlete's health, Journal of Sports Medicine and Physical Fitness. 2018; 58 (7-8), 1135-1145.

Mazzeo F., Rinaldi M., Tafuri D., Sports and supplements: Educating to well-being through effective nutrition, Sport Science. 2020; 13, 70-75.

Mazzeo F., Santamaria S., Donisi A., Montesano P., Use and attitudes toward dietary supplements and drugs amongst Italian elite athletes and its correlation with banned doping substances, Journal of $\begin{array}{llll}\text { Human Sport and Exercise. 2019; } 14 \quad \text { (Proc4), } & \text { S970-S980. }\end{array}$ https://doi.org/10.14198/ihse.2019.14.Proc4.59 
Mazzeo, F. (2016). Drug abuse in elite athletes: Doping in sports. Sport Science, 9(2), 34-41.

Mazzeo, F., Santamaria, S., \& Montesano, P. (2019). Gender difference, nutritional supplements and drug use in sport to enhancing performance: An italian revision over the last decade. Sport Mont, 17(1), 69-73. https://doi.org/10.26773/smj.190212

Mazzeo, F., Santamaria, S., Montesano, P., Rinaldi, M., \& Madonna, G. (2020). Updated evidence report for the anti-doping research: Analysis from 2008 to 2018 for performance-enhancing drugs and gene doping test development. Journal of Physical Education and Sport, 20, 2378-2385. https://doi.org/10.7752/jpes.2020.s4324

Montesano P., Di Silvestro M., Cipriani G., Mazzeo F., Overtraining syndrome stress and nutrition in football amateur athletes, Journal of Human Sport and Exercise. 2019; 14 (Proc4), S957-S969. https://doi.org/10.14198/ihse.2019.14.Proc4.58

Montesano, P., Tafuri, D., \& Mazzeo, F. (2013). Improvement of the motor performance difference in athletes of weelchair basketball. Journal of Physical Education and Sport, 13(3), 362-370. https://doi.org/10.7752/jpes.2013.03058

Montesano, P., \& Mazzeo, F. (2019a). Improvement in soccer learning and methodology for young athletes. Journal of Physical Education and Sport, 19, 795-801. https://doi.org/10.7752/jpes.2019.s3113

Montesano, P., \& Mazzeo, F. (2019b). Sports activities in obese teenagers improve social inclusion and health. Sport Mont, 17(1), 55-60. https://doi.org/10.26773/smj.190210

Montesano, P., Masala, D., Di Silvestro, M., Cipriani, G., Tafuri, D., \& Mazzeo, F. (2020). Effects of combined training program, controlled diet and drugs on middle-distance amateur runners: A pilot study. Sport Science, 13(1), 17-22.

Motola, G., Russo, F., Mazzeo, F., Rinaldi, B., Capuano, A., Rossi, F., \& Filippelli, A. (2001). Over-thecounter oral nonsteroidal anti-inflammatory drugs: A pharmacoepidemiologic study in southern italy. Advances in Therapy, 18(5), 216-222. https://doi.org/10.1007/BF02853167

Mudrak J., Slepicka P., Slepickova I., Sport motivation and doping in adolescent athletes, PLoS ONE. 2018; 13(10): e0205222. https://doi.org/10.1371/journal.pone.0205222

Schenone, S., Bruno, O., Ranise, A., Brullo, C., Bondavalli, F., Filippelli, W., . . Falcone, G. (2003). 2aryl-3-phenylamino-4,5-dihydro-2h-benz[g]indazoles with analgesic activity. Farmaco, 58(9), 845849. https://doi.org/10.1016/S0014-827X(03)00142-3

WADA, 2021 World Anti-Doping Code: International Standard for Education.

WADA, Anti-Doping E- Learning (ADEL). Available online from https://www.wada-ama.org/en/what-wedo/education-prevention/anti-doping-e-learning-adel

WADA, World Anti-Doping Agency: Model for Core Programs. Information/Education Guidelines to Prevent Doping in Sport (Version 3.0. May 2016).

Wang K., Xu L., Zhang J., Jimeng Z., Dong W., Kaihong S., Relationship between perfectionism and attitudes toward doping in young athletes: the mediating role of autonomous and controlled motivation, Subst Abuse Treat Prev Policy. 2020; 15 -20. https://doi.org/10.1186/s13011-020-00259$\underline{5}$

Woolf, J. J. R. (2020). An examination of anti-doping education initiatives from an educational perspective: Insights and recommendations for improved educational design. Performance Enhancement and Health, 8(2-3). https://doi.org/10.1016/j.peh.2020.100178

World Anti-Doping Agency (WADA), 2021 World Anti-Doping Code. Available online from: https://www.wada-ama.org/en/resources/the-code/2021-world-anti-doping-code

Zucchetti, G., Candela, F., \& Villosio, C. (2015). Psychological and social correlates of doping attitudes among Italian athletes. International Journal of Drug Policy, 26(2), 162-168. https://doi.org/10.1016/i.drugpo.2014.07.021 


\section{(c) $(1)(9)$}

This work is licensed under a Attribution-NonCommercial-NoDerivatives 4.0 International (CC BY-NC-ND 4.0). 